\title{
Analysis of Speeds of Cylinders of Saw Gins and Linters and Determination of Critical Frequencies for them
}

\author{
Akmal Umarov, Kamola Ortikova, Akramjon Sarimsakov \\ Namangan Institute of Engineering and Technology, Namangan, Uzbekistan \\ Email: akmal.umarov@mail.ru, s.akram_82@mail.ru
}

How to cite this paper: Umarov, A., Ortikova, K. and Sarimsakov, A. (2020) Analysis of Speeds of Cylinders of Saw Gins and Linters and Determination of Critical Frequencies for them. Engineering, 12, 715-722. https://doi.org/10.4236/eng.2020.1210050

Received: August 12, 2020

Accepted: October 10, 2020

Published: October 13, 2020

Copyright $\odot 2020$ by author(s) and Scientific Research Publishing Inc. This work is licensed under the Creative Commons Attribution International License (CC BY 4.0).

http://creativecommons.org/licenses/by/4.0/

\section{(c) (i) Open Access}

\begin{abstract}
With an increase in the density of the seed roll in the roll box of the saw gin, the quality indicators of the fiber and seed are poor, energy consumption increases, machine breakdowns increase, and when the density decreases, the performance of the saw gin increases. Therefore, the density control of the seed roll is one of the important problems in the ginning process. The paper proposes a change in the rotation speed of the saw cylinder with a decrease in the diameter of its numerical linear speed and machine productivity. The article describes the problem of regulating the density of a seed roll in a saw gin of the DP series, provides an overview of work on regulating the operation of the machine, determines the dependence of the productivity of gins and linters on the state of the saw system in these machines, as well as changes in the linear speed of the saw by changing its diameter. Also, the critical speed of the gin and linter saw cylinder was determined to prevent resonance. In this case, the Simulation package of the SolidWorks computer program was used. The results of the study made it possible to adjust the speed of the cylinders when changing the diameter of the saws, which improved the productivity of the machine while maintaining the quality of the fiber and seed.
\end{abstract}

\section{Keywords}

Cotton, Saw Gin, Roll Box, Seed Roll, Productivity, Rotation Frequency, Critical Frequency, Resonance, Stiffness, Mass, Total Effective Mass, SolidWorks, Simulation

\section{Introduction}

From year to year in the world market the demand for natural fibers, especially for cotton fiber, is increasing. According to the International Cotton Advisory 
Committee (ICAC), in recent years, around 23.0 million tons of cotton fiber has been produced globally, and its demand is 24.55 million tons. Due to the intensive population increase, the demand for cotton fiber and an increase in demand for it are expected in the future [1]. Therefore, at the world level, improving the quality and reducing the cost of cotton products, creating automated, resource-saving technologies, identifying and eliminating factors that negatively affect product quality at each stage of cotton production, including in the process of separating fiber from cotton seeds in recent years becomes an important task.

The researchers performed theoretical and practical research in the field of changing the speed of saw cylinders of saw gins and linter [2]-[7].

At present, the gin of the DP series is the most widely used in the cotton ginning industry of the CIS countries, which has rather good technological indicators. But the problem of regulating the density of the seed roll has not been completely solved. The problem of optimizing the density of the seed roll can be solved by improving the geometry of the feed hopper and adjusting the frequency of rotation of the feed rolls of the feeder [2]. The analysis carried out to select the law for regulating the frequency of rotation of the feeding characteristics of the controlled object is the multi-capacity of the fiber separation line, a relatively large delay in regulation, and the smoothness of the nature of the load change [2].

Maintaining the optimum density of the seed roll in the saw gin is the most important technological and economic norm that can be solved by adjusting the speed of the electric drives of the gin feeders. To solve this problem, a regulator has been developed, the structure of which is given in [3]. Tests carried out in production conditions have shown that the use of the developed device allows to ensure a stable density of the seed roll in optimal conditions in relation to without operator intervention, in accordance with the instructions, provides an improvement in the quality of cotton fiber by an average of one class [3].

When studying processes in equipment, there is a definition and change of speeds, loads, operating time and other working bodies. In saw gins, the speed of the feed rollers is changed to adjust the density of the seed roll. We proposed changing the speed of the feed rolls by an inverter. Another advantage of the inverter is the ability to observe some of the working bodies during operation [4]. When the signal arriving at the inverter changes, the speed of the feed rollers changes synchronously. This shows the possibility of using an inverter as a regulator of the mass of seed cotton entering the roll box of the saw gin [4].

In the study [5], the process of ginning on gins of the DP brand was considered, a device for regulating the density of a seed roll by changing the speed of the motor of the feed rolls with an inverter was proposed, a device for regulating the position of the roll box depending on the current load of the saw cylinder motor was proposed, experiments were carried out on determination of the dependence of the load current of the motor of the saw cylinder and the movement of the roll box.

In the article [6], it was proposed to install side accelerators that control the speed and density of the seed roll in the roll box of the saw gin. 
The work [7] provides information on the influence of the density of the seed roll formed in the roll box on the load of the saw cylinder drive, machine performance, on the quality of fiber and seeds. As a result of research in order to maintain the density of the seed roll in the optimal range, the author proposes a saw gin with a system for regulating the density of the seed roll.

\section{Materials and Methods}

The performance of gin and linter saws mainly depends on the condition of the raw materials and saw teeth. The sharper the teeth saw, the greater the productivity. The longer the machine runs, the more saw teeth lose their performance, and machine performance decreases. Therefore, maintaining the normal state of the teeth of the saws is of great importance. To do this, it is necessary to provide the necessary degree of humidity and contamination, in particular to prevent the content of litter like stones, metal particles, etc.

In accordance with the standard, saw blades are replaced with 10 broken teeth around the perimeter of the saw or 4 broken teeth in a row. Also, saw blades change every 72 hours of work on the saw gins and 48 hours of work on the linters. Newer discs are replaced by re-milled discs with a smaller diameter, which allows reuse. With each regrinding, the diameter of the discs is reduced by $10 \mathrm{~mm}$.

The linear speed of the saw teeth also significantly affects the processes of saw ginning and lintering. But since during the regrinding of disks, their diameter decreases from $320 \mathrm{~mm}$ to $300 \mathrm{~mm}$ for saw gins and from $320 \mathrm{~mm}$ to $272 \mathrm{~mm}$ for linters, and the peripheral speed of $730 \mathrm{rpm}$ does not change, this leads to a decrease in machine performance and deterioration in product quality.

The linear speed of saw blades for these machines is determined by the following formula [8]:

$$
v_{n}=\frac{\pi d n}{60}, \mathrm{~m} / \mathrm{s} .
$$

The authors proposed to maintain the linear speed of the saw teeth by changing the peripheral speed in accordance with the diameter of the saw blades. From (1) the peripheral speed of the saw blades will have the following form:

$$
n=\frac{60 \cdot v_{n}}{\pi d}, \mathrm{rpm} ;
$$

here: $d$-saw diameter, $\mathrm{m} ; n$-peripheral speed of a saw, $\min ^{-1}$.

Table 1 and Table 2 show the change in linear speed with decreasing diameter during regrinding of disks and the change in peripheral speed in order to maintain linear speed for saw gins and linters, respectively.

The performance of machines depends on the speeds of the working bodies, with increasing speed, productivity increases. But this leads to the approach of natural frequencies to the frequencies of external influences or to their coincidence, that is, to resonance. The state of resonance is one of the dangerous phenomena in machines. Therefore, when choosing the speeds of the working bodies, it is necessary first of all to determine their critical speeds. 
Table 1. Change in linear speed of saw teeth depending on changes in the diameter of saw blades for saw gins.

The change in the linear speed of the saw teeth depending Change in peripheral speed in order to on the change in the diameter of the saw blades, $\mathrm{m} / \mathrm{s}$ maintain linear speed, rpm

$$
\begin{array}{ll}
v_{320}=\frac{\pi d n}{60}=\frac{3.14 \times 0.32 \times 730}{60}=12.2 & n=\frac{60 \cdot v_{320}}{\pi d}=\frac{60 \times 12.2}{3.14 \times 0.32}=730 \\
v_{310}=\frac{\pi d n}{60}=\frac{3.14 \times 0.310 \times 730}{60}=11.8 & n=\frac{60 \cdot v_{310}}{\pi d}=\frac{60 \times 12.2}{3.14 \times 0.31}=752 \\
v_{300}=\frac{\pi d n}{60}=\frac{3.14 \times 0.3 \times 730}{60}=11.5 & n=\frac{60 \cdot v_{300}}{\pi d}=\frac{60 \times 12.2}{3.14 \times 0.3}=777
\end{array}
$$

Table 2. Change in linear speed of saw teeth depending on changes in diameter of saw blades for linter.

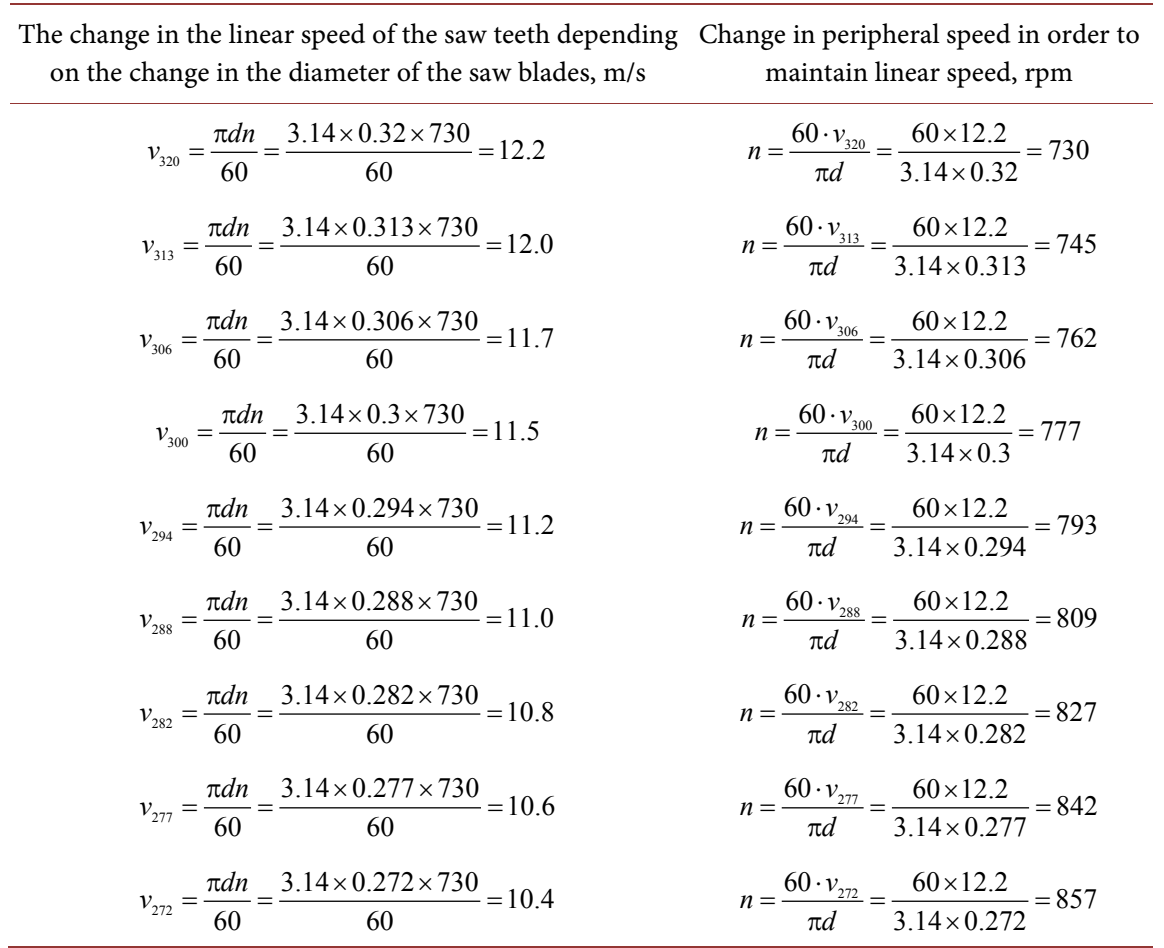

When the saw blade rotates at a speed of $730 \mathrm{rpm}$ and its diameter is $\varnothing 320$ $\mathrm{mm}$, the linear speed of the saw teeth is $12.2 \mathrm{~m} / \mathrm{s}$. But if the blade diameter is reduced by $\varnothing 310 \mathrm{~mm}$ and $\varnothing 300 \mathrm{~mm}$ for saw gins, their linear speed will be 11.8 $\mathrm{m} / \mathrm{s}$ and $11.5 \mathrm{~m} / \mathrm{s}$, respectively. This will lead to a decrease in productivity by $3 \%$ - $6 \%$. In order to maintain the performance of the machine, it was proposed to maintain a linear velocity of the saw teeth of $12.2 \mathrm{~m} / \mathrm{s}$. That is, with a saw blade diameter of $\varnothing 310 \mathrm{~mm}$, it is necessary to provide a peripheral speed of $752 \mathrm{rpm}$, and at $\varnothing 300 \mathrm{~mm}-777 \mathrm{rpm}$. To do this, it is proposed to control the peripheral speed of the saw cylinder electric motor by a frequency converter.

The next task is to determine the critical speed of the saw cylinder, for which the Simulation package of the SolidWorks computer program was used. All the necessary details of the saw cylinder were modeled in $3 \mathrm{D}$, materials for them 
were selected and assembly was performed (Figure 1).

From a review of the literature [7], a design diagram of the critical speed of the saw cylinder was adopted (Figure 2).

So, with increasing dimensions of the part in order to strengthen it, the mass also increases. As a result, its natural frequency decreases, i.e. decreases the working speed of the working body.

In the cotton industry, rigid shafts are mainly used, since their rotational speed is below the first critical speed. Based on practice, it is recommended to use the condition $n_{1 c r} \geq 1.3 n_{w}$ between the working speed $n_{w}$ and the first critical speed $n_{1 c r}$ for hard shafts [9].

\section{Results}

Using the SolidWorks Simulation program to determine the natural frequency of the saw gin shaft, the hinge was chosen as the support, and the distributed load was the distributed mass $q=320 \mathrm{~kg}$. In Figure 3(a), a plot of the natural frequency of the saw gin shaft is presented.

When determining the natural frequency, it is necessary to determine the effective total mass. The SolidWork Simulation program has the ability to determine the effective total mass, which is shown in Figure 3(b).

As can be seen from the table, the first critical frequency is $18.5 \mathrm{~Hz}, \approx 38 \%$ of the shaft mass is involved along the axis $X$, and $\approx 39 \%$ along the axis $Y$. In the second critical frequency, which is $28.0 \mathrm{~Hz}, \approx 37 \%$ is involved along the axis $X$, and $\approx 36 \%$ of the shaft mass along the axis $Y$. The most dangerous frequency along the axis $Z$ is the 7 -mode, which amounted to $186.4 \mathrm{~Hz}$, and $\approx 88 \%$ of the shaft mass is involved.

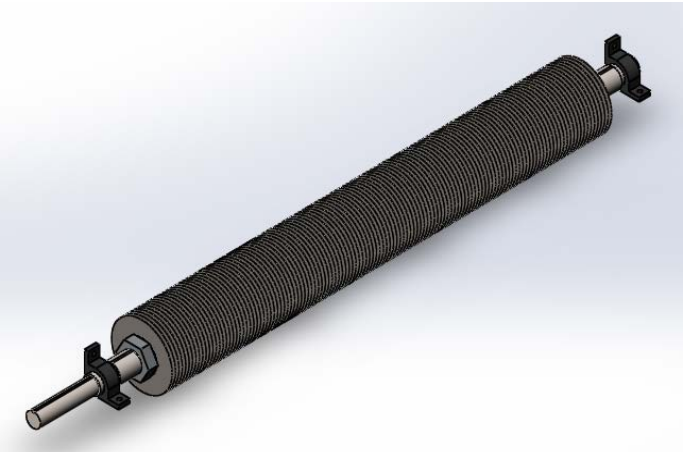

Figure 1. General view of the saw gin saw cylinder in SolidWorks.



Figure 2. The design scheme of the saw cylinder to determine its critical speed. 


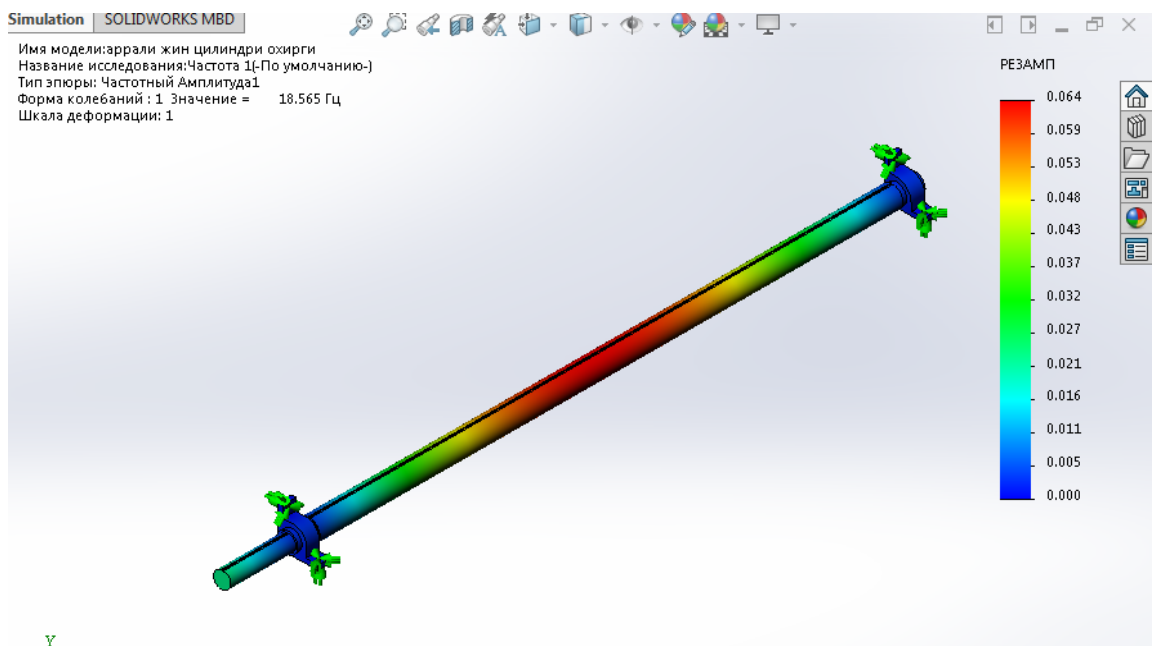

(a)

\begin{tabular}{|c|c|c|c|c|}
\hline \multicolumn{4}{|c|}{ The massive participation (normalize) } & \begin{tabular}{|l|l|l|}
$口$ & 回 & $x$ \\
\end{tabular} \\
\hline \multicolumn{5}{|c|}{ Study name: Frequency1 } \\
\hline Mode No. & Frequency (Hertz) & Direction X & Direction Y & Direction Z \\
\hline 1 & 18.565 & 0.37931 & 0.38919 & $1.4424 \mathrm{e}-007$ \\
\hline 2 & 28.048 & 0.36889 & 0.35845 & $1.0257 \mathrm{e}-009$ \\
\hline 3 & 62.006 & 0.00013831 & 0.00014071 & 0.012192 \\
\hline 4 & 79.553 & $2.7982 \mathrm{e}-005$ & 2.3191e-005 & $3.6103 e-006$ \\
\hline 5 & 138.75 & 0.035139 & 0.042064 & 0.00016714 \\
\hline 6 & 157.82 & 0.059402 & 0.052941 & $1.0306 e-007$ \\
\hline 7 & 186.38 & 0.00047395 & 0.00048904 & 0.8768 \\
\hline 8 & 238.7 & $2.5574 \mathrm{e}-005$ & $4.4463 e-005$ & $1.3367 \mathrm{e}-005$ \\
\hline 9 & 242.62 & 0.0011301 & 0.0012857 & 0.10041 \\
\hline \multirow[t]{2}{*}{10} & 260.33 & 0.00055353 & 0.00035717 & \multirow{2}{*}{$\begin{array}{c}0.000174 \\
\text { Sum } Z=099078\end{array}$} \\
\hline & & Sum $X=0.84509$ & Sum $Y=0.84490$ & \\
\hline Close & & $\mathrm{Sa}$ & & Reference \\
\hline
\end{tabular}

(b)

Figure 3. Diagram of the first natural frequency of the saw gin shaft (a) and effective total mass (b).

The sum of the frequencies in the column is called the effective total mass, $85 \%$ is recommended. In our example, the effective total masses are $\sum X \approx 85 \%$, $\sum Y \approx 85 \%, \quad \sum Z \approx 99 \%$, which fulfills the condition.

So, in our case, the first critical frequency was $18.6 \mathrm{~Hz}$. We will use $1 \mathrm{~Hz}=60 \mathrm{rpm}$ it to convert it to peripheral speed. As a result, the first critical shaft speed was $18.6 \mathrm{~Hz}=60 \times 18.6=1116 \mathrm{rpm}$.

From the condition $n_{1 c r} \geq 1.3 n_{w}$ we find $n_{w}$ :

$$
\frac{n_{1 c r}}{1.3} \geq n_{w} ; \frac{1116}{1.3} \geq n_{w} ; 858.5 \mathrm{rpm} \geq n_{w} .
$$

The maximum peripheral speed of the saw was $n_{w}=777 \mathrm{rpm}$ at a saw diameter of Ø300 mm, i.e. the condition $858.5 \mathrm{rpm} \geq 777 \mathrm{rpm}$ is fulfilled.

Using the above methodology, the SolidWorks Simulation program determines the natural frequency of the linter shaft. The hinge is chosen as the support, and the distributed mass $q=260 \mathrm{~kg}$ is the external load. The results are shown in Figure 4(a). 


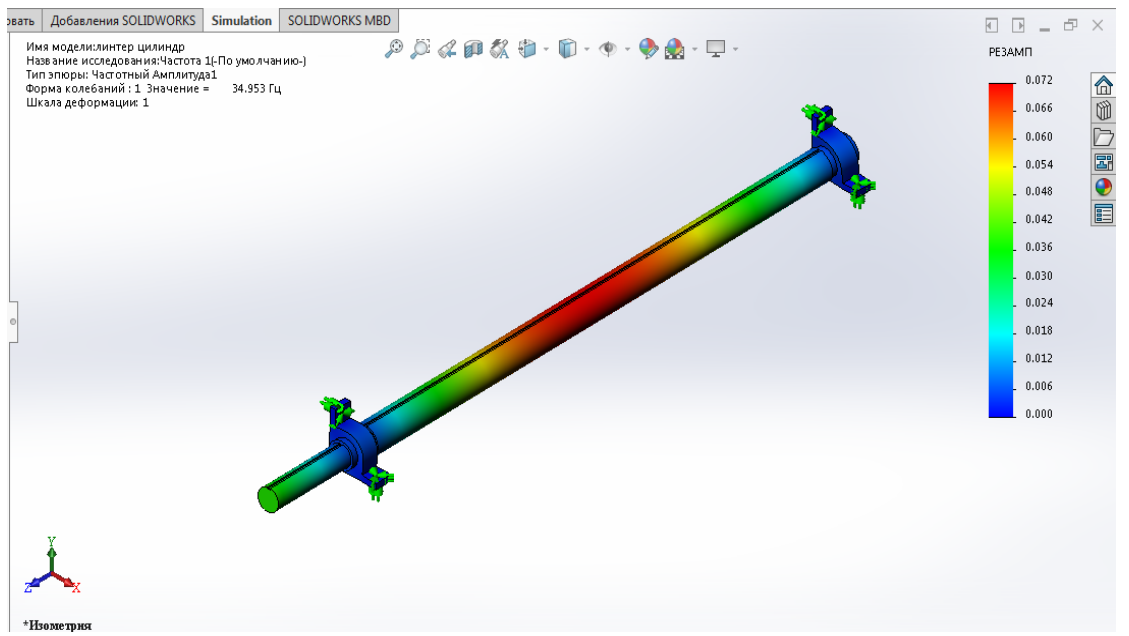

(a)

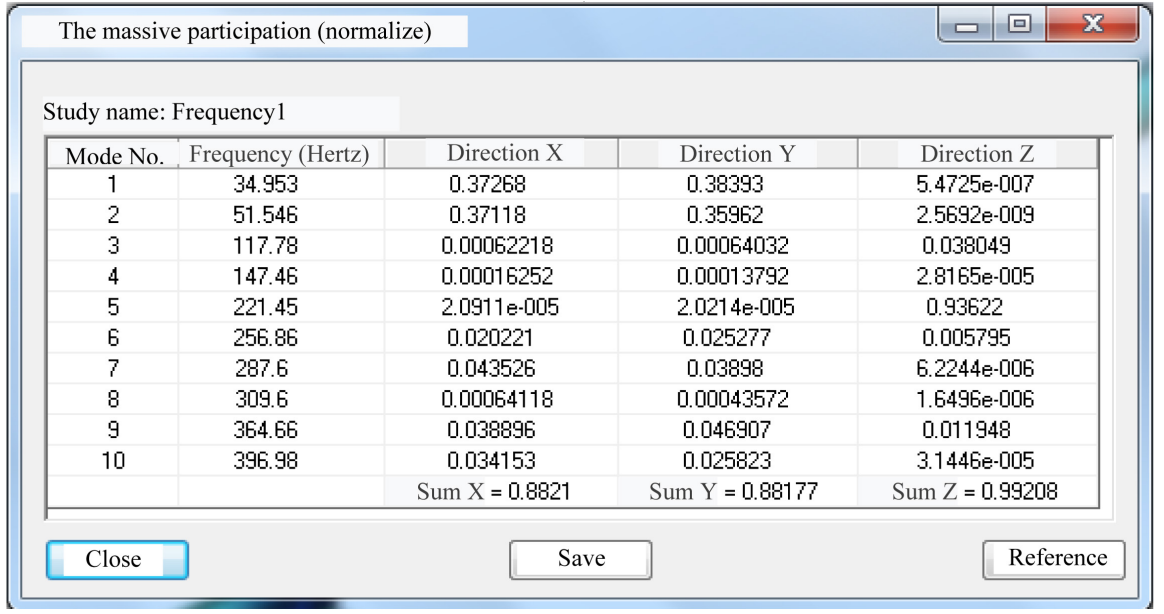

(b)

Figure 4. The plot of the first natural frequency of the shaft of the linter (a) and the effective total mass (b).

The first critical frequency of the linter shaft was $34.9 \mathrm{~Hz}$ (Figure 4(b)). Convert it to peripheral speed $34.9 \mathrm{~Hz}=60 \times 34.9=2094 \mathrm{rpm}$.

From the condition $n_{1 c r} \geq 1.3 n_{w}$ we find $n_{w}$ :

$$
\frac{n_{1 c r}}{1.3} \geq n_{w} ; \frac{2094}{1.3} \geq n_{w} ; 1610.7 \mathrm{rpm} \geq n_{w} .
$$

From the studies, the maximum peripheral speed of the linter shaft was $n_{w}=857 \mathrm{rpm}$ at a saw diameter of $\varnothing 272$, i.e. the condition $1610.7 \mathrm{rpm} \geq 857 \mathrm{rpm}$ is satisfied.

\section{Conclusions}

As can be seen from the tables, to maintain the linear speed of the saw teeth when changing the diameter of the saws, it is necessary to change their peripheral speed. This is ensured by changing the peripheral speed of the electric motor through regulation by a frequency converter. The critical speed in the studied range does 
not prevent the peripheral speed of the saw cylinder from increasing as the diameter of the saw blade decreases in order to increase productivity. The change in the speed of the saw cylinders of the saw gin and the linter will be controlled by changing the peripheral speed of the electric motor using a frequency converter.

The results of the study make it possible to use the possibility of regulating the peripheral speed of the saw cylinder of the saw gin and linter for the linear speed of the saws. This will increase the performance of the machines while maintaining the quality of the fiber and seed. According to the data obtained in the article, the peripheral speed will change at different diameters of the saws of the saw gin and linter. The results will be used in further experimental studies to study qualitative and quantitative indicators when changing the peripheral speed of the saw cylinder.

\section{Conflicts of Interest}

The authors declare no conflicts of interest regarding the publication of this paper.

\section{References}

[1] International Cotton Advisory Committee. Washington, From the Secretariat of the ICAC. https://icac.org

[2] Umarov, A. (2008) Investigation of the Regulation of the Density of the Seed Roll of the Saw Gin. Natural and Technical Sciences, Moscow, 34, 333-334.

[3] Abduvakhidov, M.A. and Umarov, A.A. (2008) Research of Speed Regulation of Electric Drives of Gin Feeders. Natural and Technical Sciences, Moscow, 34, 328-329.

[4] Axmedxodjayev, Kh., Umarov, A. and Ortiqova, K. (2019) Investigation of the Ginning Process on ДП Series Saw Gin Stands. Engineering, 11, 523-530. https://doi.org/10.4236/eng.2019.118036

[5] Umarov, A., Akhmedkhodzhaev, Kh., Sarimsakov, A. and Kenjaeva, M. (2018) Movement Differential Equation of Seed Roller which Has Been Installed Stake Accelerator on the Roll Box of Gin Machine. Engineering, 10, 521-529. https://doi.org/10.4236/eng.2018.108038

[6] Sarimsakov, A., Muradov, R., Umarov, A. and Kurbanov D. (2018) The Saw Gin Stand with Adjustable Movement of the Roll Box. Engineering, 10, 486-494. https://doi.org/10.4236/eng.2018.108034

[7] Umarov A.A. (2018) A Saw Gin with a System for Controlling the Density of a Seed Roll. Scientific-Technical Journal, 22, 52-57. https://uzjournals.edu.uz/ferpi/vol22/iss1/33

[8] Miroshnichenko, G.I. (1972) Fundamentals of Designing Machines for Primary Processing of Cotton. Mechanical Engineering, Moscow, 486 p.

[9] Makarov, A.I., Ed. (1976) Fundamentals of Designing Textile Machines. Mechanical Engineering, Moscow, $416 \mathrm{p}$. 